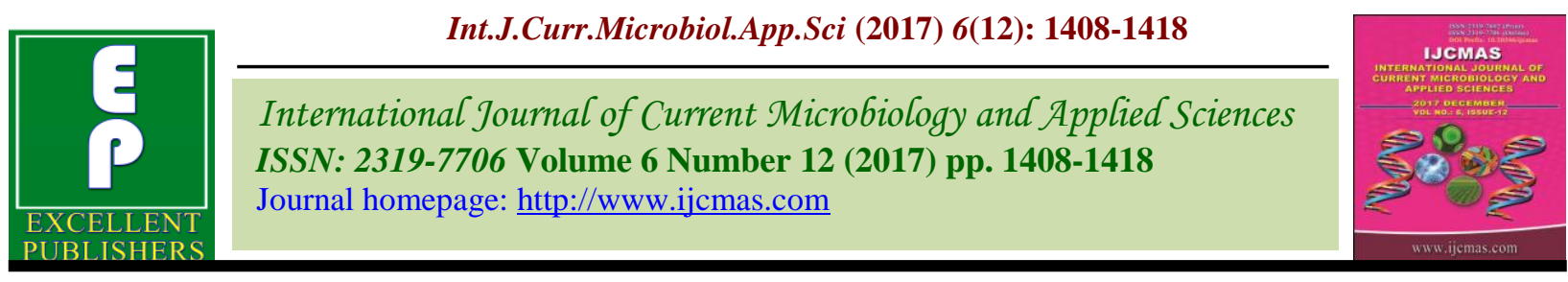

Review Article

https://doi.org/10.20546/ijcmas.2017.612.158

\title{
Yoghurt: A Predigested Food for Lactose-Intolerant People
}

\author{
Rekha Sansanwal*, Umang Ahlawat and Rinku Dhanker \\ Department of Microbiology, CCS HAU, Hisar, Haryana, India \\ *Corresponding author
}

A B S T R A C T

\begin{tabular}{|l|}
\hline Ke y w or d s \\
Yoghurt, \\
Predigested food, \\
Lactose.
\end{tabular}

Yoghurt is a food produced by bacterial fermentation of milk. The bacteria used to make yoghurt are known as "yoghurt cultures". Fermentation of lactose by these bacteria produces lactic acid, which acts on milk protein to give yogurt its texture and characteristic tart flavor. Cow's milk is commonly available worldwide, and, as such, is the milk most commonly used to make yogurt. Milk from water buffalo, goats and yaks is also used to produce yogurt where available locally. Yoghurt is produced using a culture of Lactobacillus delbrueckii subsp. bulgaricus and Streptococcus thermophilus bacteria. In addition, other lactobacilli and bifido bacteria are also sometimes added during or after culturing yogurt. This review summarizes about the history, production of yoghurt and importance of yoghurt for lactose intolerant people.

\section{Introduction}

Interest in the role of probiotics for human health goes back at least as far as 1908 when Metchnikoff suggested that man should consume milk fermented with lactobacilli to prolong life (Hughes a Hoover, 1991; O'Sullivan et al., 1992). Many functional characteristics of lactic acid bacteria (LAB) are responsible for their historical and modern use in food production. Several health benefits have been claimed to be associated with the consumption of fermented milk products (Le et al., 1986; Van't et al., 1989; Modler, 1990; Yamamoto et al., 1994). Although yoghurt microflora (Streptococcus thermophilus and Lactobacillus delbrueckii spp. bulgaricus) have been found to be beneficial for human health and nutrition (Deeth and Tamime, 1981; IDF, 1984).
Yoghurt is a fermented dairy product obtained from the lactic acid fermentation of milk. It is one of the most popular fermented milk products in the world and produced commercially or at home (Willey et al., 2008). In its commercial production, non-fat or low fat milk is pasteurized cooled to $43^{\circ} \mathrm{C}$ and are inoculated with known cultures of microorganisms referred to as starter cultures. The starter cultures may be a pure culture of a particular species of Lactobacillus or a mixed culture of Streptococcus thermophilus and Lactobacillus bulgaricus in a 1:1 ratio. The coccus which is the Streptococcus thermophilus grows faster than the Rod which is the Lactobacillus bulgaricus and is primarily responsible for acid production while the rod adds flavor and aroma. The 
growth of these Microorganisms causes the transformation of milk's sugar, lactose into lactic acid. This process gives yoghurt its texture. The associative growth of the two organisms results in acid production at a rate greater than that produced by them individually.

Yoghurt is generally made from a standardized mixture containing whole milk, partially defatted milk, condensed skim milk cream and nonfat dry milk. Alternatively milk may be partly concentrated by removal of 15$20 \%$ water in a vacuum pan or by heating. While the microorganisms fermenting milk confers on it certain health benefits inadequate pasteurized milk may contain microorganism of special importance to man (Boor et al., 2001). In which its presence or absence in milk may reflect success or failure of good manufacturing practice (GMP) or cause infection when consumed together with food. This is of economic significance in Africa where the HIV/AIDS and cancer scourge has left the public who consume milk products immune suppressed and prone to bacterial and fungi infection (Boor et al., 2001).

\section{The history of yoghurt}

For thousands of years yoghurt has been produced throughout the Middle East. Although no records are available regarding the origin, yoghurt is most likely evolved from the nomadic people living in the Middle East part of the world. The production of milk in the Middle East was seasonal, being restricted to a few months of the year. The main reason for this limited availability of milk was the lack of intensive animal production. Farming was in the hands of nomadic people who moved from one area to another. Hence they were in wilderness away from cities where they could sell their animal produce. Another factor was the climate in the
Middle East. At as high as $40^{\circ} \mathrm{C}$, milk sours immediately under primitive conditions. The animals were hand-milked, no cooling of milk was possible, and contamination was unavoidable. Under these conditions transportation and keeping of milk for a long time was not possible. However, the nomadic people devised a fermentation process, which as a result led them to keep milk for long times. It was heating the milk over an open fire (Tamime and Robinson, 1985).

Heating milk resulted in;

Concentration of milk

Modification of casein in milk

Selection of thermophilic lactic acid bacteria resistant to high temperatures

Destruction of pathogenic microorganisms

Fermentation at slightly higher temperatures during cooling, and enrichment of thermophilic lactic acid bacteria.

Soured milk with thermophilic lactic acid bacteria became the preservation method of milk, and other communities learnt of this technique. As a result the product "yoghurt", coming from the Turkish name "Yogurt", has been widely accepted (Tamime and Robinson, 1985). Specific bacteria cultures, known as starters, are used for manufacturing of fermented milk products. Yoghurt is made from milk by the protocooperative action of well-known starters, namely Lactobacillus delbrueckii spp. bulgaricus and Streptococcus thermophilus. They lead to coagulation of milk by lactic acid fermentation and other products give the characteristic properties, such as acidity, aroma, and consistency. In traditional method, using a part of previous batch to inoculate a new batch, have been used for centuries. Such cultures lead to 
variable performance, however industrial production needs consistency. The method of choice is the use of bacterial strains with known physiological, biochemical and genotypic characters.

\section{Symbiotic growth of yoghurt starter bacteria}

Milk fermentation for yoghurt is done by the addition of thermophilic lactic acid bacteria for thousands of years. This is about the associative growth of microorganisms in growth medium. Symbiotic growth of thermophilic lactic starter microorganisms is based on their metabolic compatibility. It was demonstrated by Robinson et al., 2002; inoculation of mixed cultures results in the production of lactic acid $>10 \mathrm{~g} / \mathrm{L}$ in 4 hours while $2 \mathrm{~g} / \mathrm{L}$ and $4 \mathrm{~g} / \mathrm{L}$ lactic acid was obtained by the fermentation of isolated pure cultures of Lactobacillus bulgaricus and Streptococcus thermophilus. Protocooperative growth of Lactobacillus bulgaricus and Streptococcus thermophilus considerably gives better results due to cell densities, the specific growth rates, lactic acid production rates.

Streptococcus thermophilus grows more rapidly than Lactobacillus bulgaricus initially and begins to produce lactic acid. Lactic acid production results in a decrease in the $\mathrm{pH}$ of the medium. While Streptococcus thermophilus grows, it releases $\mathrm{CO}_{2}$ from the breakdown of urea and formic acid. Streptococcus thermophilus depletes the oxygen in the medium and this causes the oxidation-reduction potential more favorable for the growth of Lactobacillus bulgaricus. The increased acidity, $\mathrm{CO}_{2}$, formic acid and depletion of $\mathrm{O}_{2}$ stimulates the growth of bacilli which is more acid tolerant than Streptococcus thermophilus. Besides having a stimulatory effect on bacilli, the growth of Streptococcus thermophilus depends on the growth of Lactobacillus bulgaricus. Lactobacillus bulgaricus has higher proteolytic activity than Streptococcus thermophilus. The proteolytic enzymes of Lactobacillus bulgaricus degrade casein with the liberation of low molecular weight peptides and amino acids which have stimulatory effect on the growth of Streptococcus thermophilus (Rajagopal and Sandine, 1990). Both two microorganisms can grow at a temperature of $42-43^{\circ} \mathrm{C}$, and the optimum temperature for symbiotic growth is $42^{\circ} \mathrm{C}$. Since the optimum growth temperature for Streptococcus thermophilus is $37^{\circ} \mathrm{C}$ and $45^{\circ} \mathrm{C}$ for Lactobacillus bulgaricus, increasing the temperature above from $42^{\circ} \mathrm{C}$, the growth of lactobacilli will be favored while the temperatures below $42^{\circ} \mathrm{C}$ results in increased growth of streptococci. Either case is resulted in a deviation in the ratio of cocci to bacilli, for the optimum yoghurt the ratio should be 1:1 (Shah, 2003) (Fig. 1).

The isolation and identification of natural starters is a need not only for the dairy industry, which still import starters abroad, but also for the preservation of natural lactic acid bacteria. With this perspective, the aim of our study was the isolation of starters from artisanal yoghurts, and their biochemical and molecular characterization

\section{Role of starters in yoghurt production}

The usage of carefully selected strains as starter cultures or co-cultures in fermentation process can help to achieve in situ expression of the desired property and to maintain a product with good quality characteristics such as aroma, taste, flavour. Starter culture inoculation into the milk to during the production of yoghurt leads to production of lactic acid, aroma compounds, exopolysaccharides and inhibitor compounds which give specific characteristics to the end product. 


\section{Lactic acid production}

Lactic acid can be produced by homofermentative and heterofermentative ways in D (-) and L (+) forms. During the early fermentation $\mathrm{L}(+)$ lactic acid is produced, D (-) type is began to be produced after about second hour of fermentation and increases continuously. Typical yoghurt flavor is caused by lactic acid which imparts an acidic and refreshing taste (Chaves et al., 2002). Lactic acid has an effect on regulation of hydrolysis of casein and adsorption of some amino acids, peptides, lactose and minerals (Akın, 2006).

\section{Proteolytic activity}

The growth of lactic acid bacteria depends on some nutritional supplies of suitable sources of nitrogen and carbon. Free amino acids and peptides are present only to a limited degree in milk. Starter bacteria have limited biosynthetic capabilities. Therefore they require free amino acids for growth. One of the essential features of lactic acid bacteria used as starter must be that they possess an efficient proteolytic system enabling them to grow to high cell densities and that they have the ability to ferment lactose rapidly into lactic acid. Therefore a complement of proteinases and peptidases are essential for the degradation of milk proteins. By itself Streptococcus thermophilus has a lower proteolytic activity than Lactobacillus bulgaricus. Therefore, in dairy starter systems Streptococcus thermophilus is used in combination with lactobacilli which leads to impact flavor, texture and composition. The free amino acids arising from the proteolytic activity of Lactobacillus bulgaricus might be identified as specific growth factors for Streptococcus thermophilus (Rajagopal and Sandine, 1990). Although proteolysis causes the stimulation of bacterial growth, it has some adverse effects on fermented milk products. It was demonstrated that, the production of bitter peptides have been attributed to the proteolysis by Lactobacillus bulgaricus during storage (Renz and Puhan, 1975).

\section{Aroma production}

Fermented dairy production industry; flavour perception, which is a crucial characteristic of food industry as the sensory characteristic, is strongly based on the volatile components (Kalviainen et al., 2003). Yoghurt bacteria give the desired flavour, mouthfeel and texture which is promoted by a series of biochemical pathway in which the starter culture provide the enzymes necessary. Among all flavour compounds isolated, the most prominent ones are lactic acid and a mixture of various carbonyl compounds like acetaldehyde, ethanol, acetone, diacetyl and 2-butanone. Acetaldehyde is considered as the major flavour compound for the typical yoghurt aroma reported by many researchers (Chaves et al., 2002). The ideal yoghurt flavour is a balanced of acidity and acetaldehyde. This is achieved by culture selection, balance of rod coccus ratio, and fermentation control. The main source of acetaldeyhde is the bioconversion of threonine catalyzed by threonine aldolase of Lactobacillus bulgaricus (Frank and Hassan 1998).

\section{Exopolysaccharide production}

Several types of polysaccharides can be produced by lactic acid bacteria which will then be classified according to their location in the cell (Degeest et al., 2001). Bacterial exopolysaccharides (EPSs) are long-chain polysaccharides consisting of branched, repeating units of sugar derivates which are mainly glucose (D-glucose), galactose (Dgalactose), rhamnose (L-rhamnose), mannose, $\mathrm{N}$-acetylglucosamine, D-glucuronic acid in 
different ratios (Vaningelgem et al., 2004). Bacterial EPSs can be classified into two groups on the basis of their composition; homopolysaccharides (HoPS) and heteropolysaccharides (HePS). Basicly HoPS can be defined as polymers composed of one type of monosaccharides while HePS are the polymers of repeating units that are composed of two or more than two types of monosaccharides. EPS is economically important because it can impart functional effects on foods and may confer beneficial health. Lactic acid bacteria, producing EPS, play an important role in dairy industry by improving viscosity and the texture of fermented products (Aslim et al., 2005). There are many factors effecting EPS yield of lactic acid bacteria such as growth medium, incubation temperature, $\mathrm{pH}$, oxygen tension, agitation speed and incubation time (De vuyst et al., 2003). As a substitute for commercial stabilizers in yoghurt manufacture, EPSproducing cultures are commonly used due to reduction of synersis and improvement of product texture and viscosity. Some researchers demonstrated that EPS-producing lactic acid cultures showed higher viscosity and lower degree of synersis compared with non-EPS-producing cultures.

\section{Production of inhibitory compounds}

One of valuable properties of starter cultures is their ability to inhibit growth of undesirable microorganisms. Reduction of $\mathrm{pH}$ and production of organic acids are the primary inhibitory actions of lactic acid bacteria. Thus, the $\mathrm{pH}$ of the medium is not suitable for many of other microorganisms. Lactic starter cultures also produce nonacidic microbial inhibitors. Hydrogen peroxide in small amounts, diacetyl, bacteriocins, secondary reaction products like hypothiocyanate are the inhibitory compounds produced in small amounts by lactic acid bacteria are the nonacidic inhibitory compounds produced by lactic starters. Producing inhibitory compounds is one of the important parts of maintaining food quality for long time periods as a result of preventing contamination. Although there are several advantages for producing inhibitory compounds, production of nonacidic inhibitors by lactic acid bacteria is not necessarily advantageous such as auto inhibition by nonacidic compounds.

\section{Product description}

Yoghurt is a smooth, fermented milk product that evolved empirically some centuries ago through the growth of thermophilic (heat loving). Lactic acid bacteria, Streptococcus thermophilus and Lactobacillus bulgaricus which ferment the milks lactose to produce lactic acid. It has a characteristic acidic taste possessing $0.95-1.5 \%$ and $\mathrm{pH}$ ranging from 3.7-4.2 with viable and abundant fermenting microorganisms.

\section{Production of yoghurt}

\section{Raw materials}

In yoghurt preparation the following essential materials are use in processing the product: milk or concentrated skimmed or partly concentrated skimmed milk or milk product and the starter culture Lactobacillus bulgaricus and Streptococcus thermophilus. In. the absence of pure culture one to two spoonful of commercially purchased yoghurt can be used for the inoculation. Also, there are optional ingredients like milk powder, skimmed milk powder, flavour, colours, sugar, wheat, edible casein, preservatives, stabilizers (gelatin, locust bean gum, pectin, starch) etc.

\section{Equipments}

They include refrigerator or cooler, boiler or heater, thermometer. 
Fig.1 Growth curves of starter bacteria for pure cultures and mixed culture (Source: Tamime and Robinson 1985)
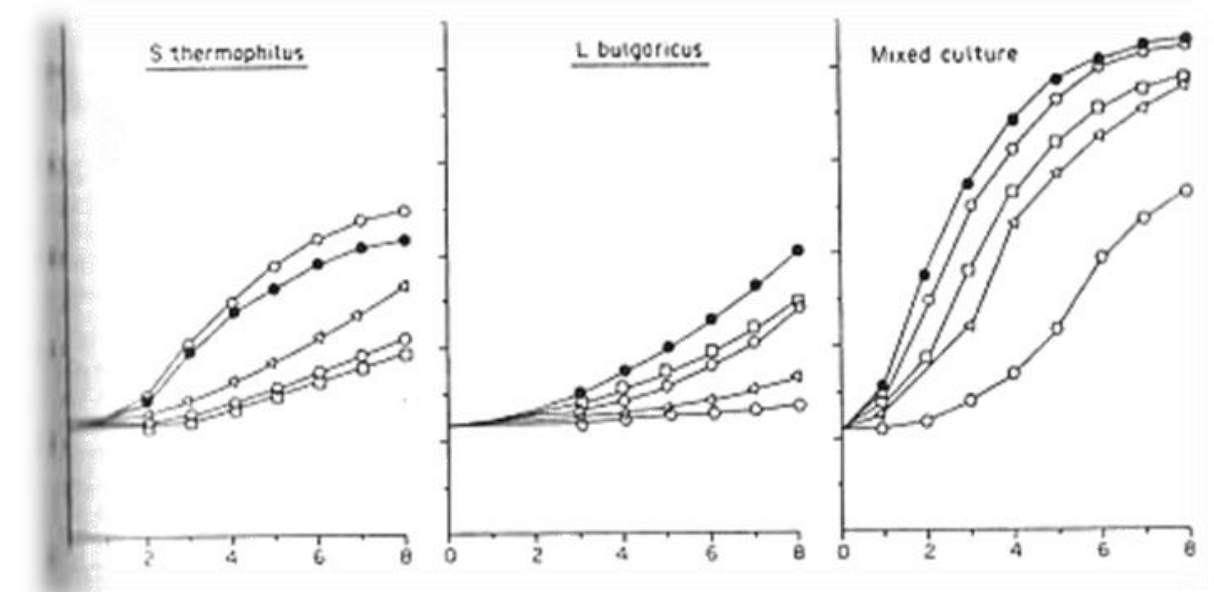

Fig.2 Stimulatory effects of two microorganisms (Source: Tekinşen, 2000)

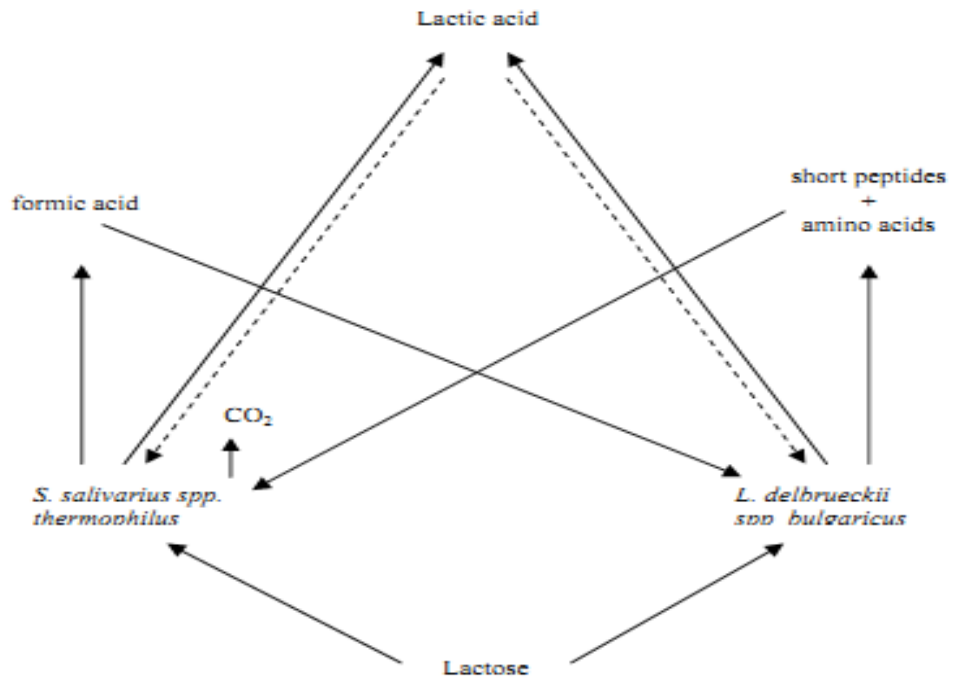

\section{Yoghurt preparation protocol}

Homogenised whole or low fat milk Addition of skim milk powder Heat treatment at $80-90^{\circ} \mathrm{C}$ for $30 \mathrm{~min}$ Cooled to $40-45^{\circ} \mathrm{C}$

Culture added $(2 \%)$ at $40-45^{\circ} \mathrm{C}$

Packaging

Incubation at $42^{\circ} \mathrm{C}$

Storage at $4^{\circ} \mathrm{C}$

\section{Traditional method of yoghurt making}

Many fermented foods are still produced either by natural (spontaneous) fermentation or by back-slopping and the active cultures may be poorly defined. Natural fermentation is the process initiated without the use of starter inoculum. Natural fermentation results from competitive activities of contaminating organisms. In small-scale fermentations and 
in rural (regional) areas in the countries where yogurt is originated, material from a previous successful batch is added to facilitate the initiation of a new process for the production of traditional yogurt called back slopping.

Through this repeated practice of backslopping, selection of best adapted strains can naturally be achieved., spontaneous food fermentations are neither predictable nor controllable, particularly in large-scale production. Therefore, in the industry, commercially produced starter cultures are preferred for standardization and safety reasons during yogurt production.

The milk is evaporated to $1 / 3$ to $1 / 4$ water content so that it attains the required concentration. Alternatively, 4-5\% non-fat dried milk (NFDM) can be added to the whole milk. It is heated to $82-93^{\circ} \mathrm{C}$ for 30 minutes. Then it is cooled to $42-43^{\circ} \mathrm{C}$ and inoculated with $2-3 \%$ starter culture (Lactobacillus bulgaricus and Streptococcus thermophilus).Then the milk is incubated at $42-43^{\circ} \mathrm{C}$ for 3 hours or until a titrable acidity of $0.75 \%$ lactic acid or coagulation occurs. The product is chilled to $5^{\circ} \mathrm{C}$. Further acidity of $0.9 \%$ lactic acid may develop while the product is being chilled. The product can be stored satisfactorily for $1-2$ weeks at $5^{\circ} \mathrm{C}$.

\section{Industrial method of yoghurt making}

The desired quantity of milk is weighed and heated to $80-90^{\circ} \mathrm{C}$ for $15-20$ minutes. Then it is cooled to $45-48^{\circ} \mathrm{C}$. Two to three percent of yoghurt culture is added to the milk and mixed well. The milk is kept in clean and sterilized containers for setting. The milk in the container is incubated at $45^{\circ} \mathrm{C}$ until the coagulation is firmer. The product is removed from the incubator and kept at $5^{\circ} \mathrm{C}$ until distributed to the consumers. The equipment are cleaned and kept ready for the next batch of operation (Tamine and Robinson, 2004).

\section{Varieties in yoghurt presentation}

Yoghurt has been described as a notoriously balanced food, containing almost the nutrients present in milk but in a more assimilable form. The can be produced from whole or skimmed milk (Ojokoh, 2006). There are large ranges of flavors enhancer available commercially that can be used in the production of yoghurt and yoghurt is typically categorized as follows:

\section{Set yoghurt}

This type of yoghurt is incubated and cooled in the final package and is characterized by a firm Jelly-like texture.

\section{Stirred yoghurt}

This type of yoghurt is incubated in a tank and the final coagulum is "broken" by stirring prior to cooling and packaging. The texture of stirred yoghurt will be less firm than a yoghurt not stirred which is somewhat like a very thick cream. There is some slight reformation of the coagulum after the yoghurt has been packed, however this is slight and cannot be relied upon.

\section{Drinking yoghurt}

This type of yoghurt is very similar to stirred yoghurt, having the coagulum "broken" prior to cooling. In drinking yoghurt, the agitation used to "break" the coagulum is severe. Little care is applied if any reformation of the coagulum will reoccur after packing.

\section{Frozen yoghurt}

This is inoculated and incubated in the same manner as stirred yoghurt. However, cooling is achieved by pumping through a whipper/chiller/freezer in a fashion similar to the cream. The texture of the finished product 
is mainly influenced by the whipper/freezer and the size and distribution of the ice crystals produced.

\section{Concentrated yoghurt}

This type is inoculated and fermented in the same way as stirred yoghurt, following the "breaking" of the coagulum. The yoghurt is concentrated by boiling off some of the water. This is often done under vacuum to reduce the yoghurt often lead to protein being totally denatured and producing rough and gritty texture. This is called strained yoghurt due to the fact that the liquid that is released from the coagulum upon heating used to be "strained" off in a manner similar to making of soft cheese.

\section{Flavoured yoghurt}

Yoghurt with various flavours and aromas has become very popular. The following are usually added at or just prior to filling into pots. Common additions are fruits or berries, usually as a pure or as whole fruit in syrup. These additives often have" as much as 50\% sugar in them. However, with the trend towards healthy eating gained momentum many manufacturers offer a low sugar and low fat version of their products. Low or no sugar yoghurts are often sweetened with saccharin or more commonly aspartame. The use of a "fruit sugar" in the form of concentrated apple juice is sometimes found as a way of avoiding' "additional sugar" on the ingredients declaration. This tends to be a market ploy and has no real added benefits.

\section{Therapeutic benefits of yoghurts}

\section{Yoghurt is easier to digest}

Many people who cannot tolerate milk, either because of protein allergy or lactose intolerance, can enjoy yogurt. The live active cultures create lactase, the enzyme lactoseintolerant people lack, and another enzyme contained in some yogurts (betagalactosidase) also helps to improve lactose absorption in lactase-deficient persons. The culturing process has already broken down the milk sugar lactose into glucose and galactose, two sugars that are easily absorbed by lactose-intolerant persons.

\section{Yogurt contributes to colon health}

Yogurt contains lactic acid bacteria, intestinefriendly bacterial cultures that foster a healthy colon, and even lower the risk of colon cancer.

Lactic acid bacteria, especially acidophilus, promote the growth of healthy bacteria in the colon and reduce the conversion of bile into carcinogenic bile acids.

The more of these intestine-friendly bacteria that are present in the colon lower the chance of colon diseases. Basically, the friendly bacteria in yogurt seems to deactivate harmful substances (such as nitrates and nitrites before they are converted to nitrosamines) before they can become carcinogenic.

Yogurt is a rich source of calcium - a mineral that contributes to colon health and decreases the risk of colon cancer. Calcium discourages excess growth of the cells lining the colon, which can place a person at high risk for colon cancer. Calcium also binds cancerproducing bile acids and keeps them from irritating the colon wall.

\section{Yogurt improves the bioavailability of other nutrients}

Culturing of yogurt increases the absorption of calcium and B-vitamins. The lactic acid in the yoghurt aids in the digestion of the milk calcium, making it easier to absorb. 


\section{Yogurt can boost immunity}

The bacterial cultures in yogurt have also been shown to stimulate infection-fighting white cells in the bloodstream. Some studies have shown yogurt cultures contain a factor that has anti-tumor effects in experimental animals.

\section{Yogurt aids healing after intestinal} infections

Some viral and allergic gastrointestinal disorders injure the lining of the intestines, especially the cells that produce lactase. This results in temporary lactose malabsorption problems. This is why children often cannot tolerate milk for a month or two after an intestinal infection. Yogurt, however, because it contains less lactose and more lactase, is usually well-tolerated by healing intestines and is a popular "healing food" for diarrhea.

A study reported in 1999 in pediatrics showed that lactobacillus organisms can reduce antibiotic-associated diarrhea.

\section{Yogurt can decrease yeast infections}

Yogurt that contains live and active cultures daily reduces the amount of yeast colonies and decreases the incidence of yeast infections.

\section{Yogurt is a rich source of calcium}

Because the live-active cultures in yogurt increase the absorption of calcium, an 8ounce serving of yogurt gets more calcium into the body than the same volume of milk can.

\section{Yogurt is an excellent source of protein}

Eight ounces of yogurt that contains live and an active culture contains 20 percent more protein than the same volume of milk (10 grams versus 8 grams). Besides being a rich source of proteins, the culturing of the milk proteins during fermentation makes these proteins easier to digest. For this reason, the proteins in yogurt are often called "predigested."

\section{Yogurt can lower cholesterol}

There are a few studies that have shown that yogurt can reduce the blood cholesterol. This may be because the live cultures in yogurt can assimilate the cholesterol or because yogurt binds bile acids.

\section{Factor that alter the quality of yoghurt}

\section{Milk quality}

The milk used for yoghurt manufacture should be of the highest bacterial quality available. It should also have an absence of any material that will impede or prevent the growth of the starter microorganism, (antibiotics, preservative, disinfectants, and bacteriophages).

\section{Bacteriophages}

Bacteriophages are a group of virus that attacks the yoghurt starter organisms, a whole range of defects can be attributed to the action of this bacteriophage.

Bacteriophage normally referred to just as "phage" are the most likely cause of long or never-ending incubations. Large manufacturers that have laboratory facilities to check incoming milk will often eliminate the possibilities of other starter inhibiting substances but "Phages" are usually found in the drains and floor gullies of a dairy producing any cultured product, poor hygiene and lack of general housekeeping increase the risk. 


\section{Starter culture}

The starter culture is the term generally applied to organisms used to ferment a cultured product (Cheese, Yoghurt, and Kefir). The microorganisms selected for this purpose need to produce the desired effect in the product. For normal commercial yoghurt the starter must be capable of fermenting lactose and producing lactic acid, little if any carbon dioxide is required and the flavour and aroma must be clean and fresh. Traditionally when a suitable starter organism had been found on a large quantity would be grown in a suitable nutrient medium and small quantities would be used to inoculate each new batch of yoghurt. This technique with a main batch of starter culture is often referred to as using "bulk starter". The use of a bulk starter is becoming increasingly uncommon amongst commercial producers, mainly because of the risk of "Phage" attack on the bulk starter, and the subsequent lost time while a new batch of starter organisms are prepared. A technique often referred to as Direct Vat Inoculation (DVI) is becoming the industry norm. DVI involves inoculating the yoghurt mix directly with a very large number of freeze dried starter organisms. The advantage of relative immunity to "Phage" attack for outweighs the slightly longer incubation time required with this technique.

\section{Fat percentage}

The percentage of fat in the final yoghurt has a significant effect on the "mouth feel", the normal range of fat content is from $0.5 \%$ to about $3.5 \%$, however levels as low as $0 \%$ and as high as $10 \%$ are found in some specialty products.

\section{References}

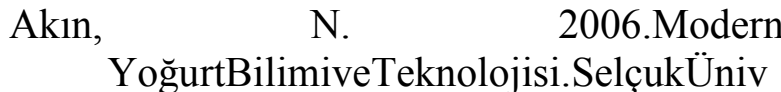

ersitesiZiraatFakültesi, GıdaMühendisliğiBölümü, Konya.23$25 \mathrm{p}$

Aslim B, Yüksekdag Z N, Beyatli Y. 2005. Exopolysaccharide production by Lactobacillus delbrueckii ssp. bulgaricus and Streptococcus thermophilus strains under different growth conditions. World $J$. Microbiol.Biotechnol, 21:673-677.

Boor K J. 2001. Fluid dairy product quality and safety: looking to the future. $J$. Dairy Sci, 84:1-11

Chaves A, Fernandez M, Lerayer S, Mierau I and Kleerebezem M. 2002.Metabolic engineering of acetaldehyde production by Streptococcus thermophilus. Appl. Environ. Microbiol, 68:5656-5662.

De Vuyst L, Zamfira M, Mozzia F, Adriany T, Marshalld V, Degeest B and Vaningelgem F. 2003. Exo polysaccharide producing Streptococcus thermophilus strains as functional starter cultures in the production of fermented milks. Inter. Dairy J, 13:707-717

Deeth HC and Tamime A.Y. 1981. Yoghurt: nutritive and therapeutic aspects. Journal of Food Protection, 44:78-86.

Degeest B, De Vuyst L. and Vaningelgem F. 2001. Microbial physiology, fermentation kinetics, and process engineering of heteropolysaccharide production by lactic acid bacteria. International Dairy J, 11:747-757.

Frank J and Hassan A. 1998. Starter cultures and their use. Edited by Elmer $\mathrm{M}$ and James S. Applied Dairy Microbiology. New York: Markel Decker. 72 Pp.

Hughes DB and Hoover DG. 1991. Bifidobacteria: Their potential for use in American dairy products. Food Technol, 45(4): 74-83.

International Dairy Federation (IDF), 1984.Dairy effluents. Proceedings of an 
IDF Seminar, Killarney, Ireland. April, 1983. Bulletin of IDF, Number 184.

Kalviainen N, Roininen $\mathrm{K}$ and Tuorila $\mathrm{H}$. 2003. The relative importance of texture, taste and aroma on a yogurt-type snack food preference in yhe young and the elderly. Food Qual. Pref., 14:177-186

Le M.G, Moulton LH, Hill C and Kramar A, 1986. Consumption of dairy produce and alcohol in a case control study of breast cancer. J. Nat. Cancer Instl, 11: 633.

Modler HW, Mckeller RC and Yaguchi M. 1990. Bifidobacteria and bifidogenic factors. Canad. Inst. Food Sci. Technol. $J, 23(1): 29$.

O'Sullivan MG, Thornton G, O'Sullivan GC and Collins JK. 1992. Probiotic bacteria: myth or reality? Trends Food Sci. Technol, 3: 309-314.

Ojokoh A O. 2006: Roselle (Hibiscus Sabdariffa) calyx diet and histopathological changes in liver of Albino rats. Pak. J. Nut. 5(2): 110-113.

Rajagopal SN and Sandine WE. 1990. Associative growth and proteolysis of Streptococcus thermophilus and Lactobacillus bulgaricus in skim milk. J. dairy sci, 73:894-899.

Renz U and Puhan Z, 1975.Factors promoting bitterness in yoghurt. Milchwissenschaft, 30265.

Robinson, R.K. 2002. "Fermented Milks:
Yoghurt, Role of Starter Cultures" in Encyclopedia of Dairy Science, edited by H. Roginski, J. Fuquay, P. Fox (Academic Press, United Kingdom). 245p.

Shah N. 2003. The product and its manufacture. In Encylopedia of Food Science and Nutrition. Edited by Cabarello B, Trugo L, Finglas P. London: Academic Press. 6252-62p.

Tamime and Robinson (1985). Yoghurt: science and technology, Oxford, New York: Pergamon, 1985.

Tekinsen, O.C., Tekinsen, K.K. (2005). Sutve Sut Urunleri: Temel Bilgiler, Teknoloji, Kalite Kontrolu. Selcuk Universitesi Basimevi, Konya, Turkiye. 43:181-184

Van't, VP, Dekker JM, Lemers JWJ, Kok FJ, Schouten EG, Brants HAM, Sturmans F and Hermus RJJ. 1989. Consumption of fermented milk products and breast cancer: a case control study in the Netherlands. Cancer Res, 49:402

Willey JM, Sherwood LM and Woolverton CJ. 2008. Prescott, Harley and Kleins's Microbiology. 7th Edn, McGraw-Hill Higher Education, USA. 1088p.

Yamamoto N, Akino A and Takano T, 1994. Antihypersensitive effects of different kinds of fermented milk in spontaneously hypersensitive rats. BioSci. Biotechnol Biochem, 58: 776.

\section{How to cite this article:}

Rekha Sansanwal, Umang Ahlawat and Rinku Dhanker. 2017. Yoghurt: A Predigested Food for Lactose-Intolerant People. Int.J.Curr.Microbiol.App.Sci. 6(12): 1408-1418. doi: https://doi.org/10.20546/ijcmas.2017.612.158 